\title{
SEMBLANZA DE MI PADRE EUGENIO COSERIU. RECUERDOS CON OCASIÓN DE LA ATRIBUCIÓN DEL GRADO DE DOCTOR «HONORIS CAUSA», IN MEMORIAM, POR LA UNIVERSIDAD DE LAS PALMAS DE GRAN CANARIA
}

\author{
EUGENIA COSERIU DE LETTNER
}

Cada vez que pienso en mi padre, Eugenio Coseriu, afluyen a mi memoria las palabras de Rubén Darío en su poema «A Roosvelt»: «primitivo y moderno, sencillo y complicado».

Se trataba, en efecto de una personalidad compleja y aparentemente contradictoria: estoico y epicúreo, racional y sentimental, austero y pasional, estricto y afectuoso.

La preeminencia que diera a ciertos aspectos de su personalidad a expensas de otros, quizás tenga su origen en un conocimiento profundo de la historia y de las ideas de los autores clásicos, es decir, de la cosmovisión que dio origen justamente a la racionalidad, a la ciencia, a la filosofía y a la conciencia histórica, esto es, a la idea de que el individuo es producto y actor de la historia y de que el pasado es condición del futuro y se perpetúa en el mismo gracias al actuar presente del ser humano orientado hacia ese fin: gracias a la transmisión del conocimiento, de la tradición y de los pensamientos y experiencias propios.

Ello exige, en efecto, que el individuo desarrolle su actividad siguiendo una línea determinada por el objetivo a alcanzar y dejando de lado los aspectos de su personalidad más desfavorables a la consecución de esa meta, que constituyen un obstáculo para el estudio sistemático de hechos e ideas y para la propagación, perpetuación y enriquecimiento de las mismas, lo cual es condición sine qua non del progreso de la historia y de la realización del individuo como agente de la misma. Dicho de otro modo: una actividad teleológica supone renunciar a todo aquello que en la naturaleza del hombre es «menos humano», a todo lo que implique ser menos dueño de sí mismo, de sus actos y de su devenir.

Por lo mismo (por esa profunda conciencia histórica) no es casual que su actividad se haya centrado en el estudio del lenguaje, puesto que éste no sólo es el instrumento de la transmisión de la tradición y de las ideas, sin la cual no hay historia posible, sino que hablar es una actividad propia del ser humano, que hace posible la interacción del mismo con el mundo exterior de una manera no puramente biológica y no como mero objeto pasivo del acontecer externo, sino como sujeto capaz de aprehender los hechos y de transmitir su experiencia y, por lo mismo, de determinar el curso de dicho acontecer externo, es decir como sujeto histórico. 
Si bien, en tanto científica, puedo entender y explicar los procesos mentales que se operan en quien entiende perpetuar y enriquecer el conocimiento humano, así como las líneas de vida necesarias a ese efecto, no soy especialista en la disciplina en la que se destacó Eugenio Coseriu. Por ello me limitaré a evocar hechos y recuerdos que revelan aspectos de su personalidad que no se manifestaron necesariamente en su vida pública y en su actividad académica y otros atenientes a su actitud en el ámbito familiar que reflejan su modo de proceder para alcanzar la meta que se había fijado.

Entre los primeros recuerdos se encuentran necesariamente los que conservo de cuando era pequeñita, de cuando, en Solís, me llevaba a nadar, agarrada yo de su cuello, y de cuando, en Montevideo, los domingos de mañana, después de ir al cine a ver dibujos animados, iba a degustar un yogur en la Conaprole de 18 de Julio y Cuareim (¿o Yaguarón?) y me quería convencer de que yo también hiciera como él, pese a tener yo otros gustos (debo confesar que, por aquel entonces, me gustaban muy pocas cosas).

También recuerdo cuando llegaba a casa con pilas de separatas y yo le decía: «Un altro libro?!». Ignoraba que esos «libros» (Sistema, norma y habla, Forma y sustancia en los sonidos del lenguaje, La geografía lingüística, La creación metafórica en el lenguaje, Logicismo y antilogicismo en la gramática, Determinación y entorno, Sincronía, diacronía e historia) se convertirían en obras capitales de la lingüística y, en general, del pensamiento científico de la segunda mitad del siglo XX. Como me comentó otro lingüista ilustre, Georges Mounin, en Aix-en-Provence, en 1974: «Votre père a renouvelé au moins 50\% de la linguistique moderne» (Su padre renovó por lo menos un 50\% de la lingüística moderna).

Todo eso no lo sabía, aunque intuía que su trabajo era importante no sólo porque lo apasionaba, no sólo por la cantidad de escritos que llegaban todos los días a casa (entre ellos recuerdo las ediciones bilingües de Platón y Aristóteles de Les Belles Lettres, con la lechuza), sino también porque, al despertarme a las seis y media de la mañana para ir al colegio, el Lycée Français de Montevideo, lo encontraba prosiguiendo el trabajo que había comenzado la noche anterior, porque vivía para sus libros, para comprar unos y producir otros, al punto de hacerse fabricar papel con camisas viejas, sin duda para disminuir los costos de producción y disponer así de más medios para enriquecer su biblioteca. Eso explica quizás que la primera obra que me compré yo por propio interés y no porque lo exigieran mis estudios fuera La República de Platón, en una lindísima edición de Eudeba, pero que (y es una lástima) estaba sólo en castellano.

Otro recuerdo son sus chistes («cargadas», como se dice en el Río de la Plata) acerca de mi intención de estudiar física : ¿Física? ¡Bah, bah, bah! ¿Una hija matemática? ¡Qué vergüenza!» No sabía que estaba pensando, quizás, en Vico y en su verum factum, del cual oiría hablar más tarde en relación con la antropología o etnología fenomenológica del Profesor Marcelo Bórmida, a quien respetaba grandemente, o quizás en Husserl y su saber originario, o en Cassirer y sus formas simbólicas, o quizás en el logos semántico o en la enérgeia aristotélicos, como tampoco sabía aún que, años después, estos y otros pensadores estarían presentes cotidianamente en mi círculo familiar más próximo.

También recuerdo que, con ocasión de una gira hispanoamericana que lo llevó de Ciudad de Méjico a Buenos Aires en 1968, me escribió una de las tres o cuatro cartas que recibí de él en toda mi vida, fechada en Maracaibo el $1^{\circ}$ de mayo, en la que me decía que el 
golpe más grande que había sufrido en su vida había sido mi decisión de no trasladarme con él a Alemania en 1963. Ese mismo año (1968) me casé con un entonces estudiante de Antropología que más tarde se doctoraría en Lingüística con Georges Mounin, casamiento cuya fecha adelantamos para que pudiera estar él presente.

Es cierto que tenía miedo a cambiar de lengua, yo que me manejé siempre con tres o más simultáneamente, cuyo pasatiempo favorito es leer el diccionario etimológico del alemán de Kluge, tenía miedo a «vivre les langues» (vivir las lenguas), como dice André Martinet, y no sabía aún que el destino me iría a llevar a Francia, a Argelia y, finalmente, a Viena, al mundo alemán.

En otra oportunidad, apareció de repente en Aix-en-Provence, a eso de las once de la noche, al regresar de un congreso, creo (¿de dónde si no?), para conocer a su primera nieta. La fue a ver dormir en su cuna y dijo que era bellísima. Se quedó a dormir más o menos como en campamento y partió a la mañana siguiente, temprano, no sin antes comprarse una «cafetera-despertador» de cuya existencia se había enterado por haber visto una en nuestra casa, hacerse rápidamente con una caja de «calissons d'Aix» y diciendo que le diéramos sus más distinguidos saludos a Georges Mounin y que le explicáramos por qué no lo había ido a ver.

Otro recuerdo es la carta que me escribió (otra de las pocas) cuando me doctoré en Física teórica en 1978, lleno de orgullo y de admiración, prueba de que sus chascarrillos sobre las matemáticas o las ciencias exactas no eran más que el reflejo de su pensar científico, que nunca cesaba, ni siquiera cuando hacía chistes, actividad que practicó hasta los últimos días de su vida (en agosto del año 2002 pasé unos diez días en Kirchentellinsfurt y sólo paró de hacer bromas para irse a dormir).

Son recuerdos familiares, sociales, pero dicen de su aspecto humano y sensible y constituyen un marco poco conocido del cuadro de su actividad y creatividad científicas.

No sé cuáles serán los recuerdos de mis hermanos, pues no estuvimos mucho en contacto, debido a la diferencia de edad (entre nueve y trece años) y a los distintos países en los que crecimos y vivimos, pero seguramente esos recuerdos han de estar también ligados a su enorme y magnífica biblioteca y a su pasión por el trabajo y por su vocación, a la coherencia de su línea de vida, ligados a sus cinco principios ético-científicos teóricos: el del realismo o de la objetividad, el del humanismo o del «saber originario», el de la tradición, el del antidogmatismo y el del bien público o de la responsabilidad social.

Son los principios que también yo y, sin duda, todos los míos hemos tratado de seguir, sin poder explicitarlos fácticamente, aunque, como diría mi padre, de ellos tenemos, al menos, la cognitio clara confusa de la que habla Leibniz [en 1684], o, como diría Hegel, ellos nos son «bekannt», pero no todavía «erkannt».

Sé que, como pasa con Husserl, cuyos manuscritos aún sin publicar lo convierten en un pensador siempre viviente y contemporáneo, los trabajos aún inéditos de Eugenio Coseriu lo convertirán en el gran lingüista del siglo XXI, contemporáneo y viviente, y que habrá generaciones de estudiosos que encontrarán inspiración y guía en su obra, no sólo científica filológica, sino también filosófica y humanista, pues el lenguaje es, como decía Hegel, la Wirklichkeit, la «realidad» de la cultura, y ello porque, como enseñaba Heráclito el Oscuro, «el logos es común». 
Lamentablemente sólo puedo hablar de mis recuerdos personales. Hubiera querido relatar uno al menos de mis otros hermanos, o de mi tía, pero de la honorable distinción de recibir este doctorado me enteré con muy poca anticipación.

Agradezco pues a la prestigiosa Universidad de Las Palmas de Gran Canaria, una tierra que fuera avanzada de la hispanidad en los tiempos del Descubrimiento, el honroso título que le ha otorgado a mi ilustre padre, así como también el haberme dado la oportunidad de lograr aunar recuerdos que, como dije, contribuyen a situar en un marco íntimo y familiar a una de las figuras más importantes de la ciencia contemporánea, marco íntimo que también coadyuvó a la maduración de las ideas que darían lugar a una Lingüística integral, síntesis y superación (en sentido filosófico) de Aristóteles y Vico, Hegel, Humboldt y Ferdinand de Saussure. 